\title{
FIRE AND EXPLOSION HAZARDS CAUSED BY OXYGEN CYLINDERS
}

\author{
BOŻENA KUKFISZ, SZYMON PTAK, MARZENA PÓŁKA \& MAREK WOLIŃSKI \\ The Main School of Fire Service, Faculty of Fire Safety Engineering, Warsaw, Poland
}

\begin{abstract}
Oxygen is an oxidising gas that is in frequent use in a compressed form. Its increased concentration causes the distension of flammability thresholds of gases and liquid vapours. Solids surrounded by oxygen burn at a higher intensity, generating greater amounts of heat and higher combustion temperatures. The hazard caused by combustion of a substance in an oxygen environment not only causes its higher intensity, but due to its impact substances which in normal use conditions would not be easy to ignite, such as plastics or metals, become easily flammable in an oxygen atmosphere. Oxygen may become absorbed (in other words be accumulated) in the structure of textile materials, of which working clothing is made. Due to the possibility of warming up oxygen cylinders, it is important to know the hazards it creates, e.g. in the case of a shot, accidental opening, water cooling, and dangerous phenomena due to the presence of other flammable gases such as acetylene. The training described in the article points to the important danger when heating cylinders and the danger resulting from attempts to eliminate a hazard, e.g., during rescue and firefighting.
\end{abstract}

Keywords: explosion hazard, fire safety, gases, oxygen.

\section{STORAGE AND USAGE OF CYLINDERS WITH OXYGEN}

Cylinders containing compressed oxygen should be stored inside premises with a temperature below $50^{\circ} \mathrm{C}$, in a well-ventilated place. They should be kept away from easily flammable gases and other flammable materials. Such cylinders should be stored in a vertical position and appropriately secured from overturning. Stored containers should be periodically checked with respect to their general state and tightness. Use should be made of caps or valve covers. All containers should be stored in a place free of any risk of a fire and away from sources of heat or ignition. Containers should not be kept in conditions facilitating corrosion. It is inadmissible to store them together with flammable materials. Should it prove to be necessary, containers and installations that carry oxygen (e.g. execution of tightness test), should be rinsed with air or oxygen. In both cases n cleansing gas should not contain any contamination, such as hydrocarbons. This concerns in particular the commonly used lubricating materials and oils. It is inadmissible to use the same hose to convey flammables gases and later for oxygen. Remnants of flammable gas may form an explosive mixture. Equipment used to carry (transport) oxygen should be adapted to the purpose, which concerns primarily materials, of which seals are made. Transported gas may commence oxidising of material of which the seals are made.

Storage of liquid oxygen should only be done in specially designated containers. Their filling should proceed slowly to avoid the occurrence of thermal shock sustained by structural materials. Access to cylinders containing oxygen should be controlled. Unauthorised persons may not have any opportunity of handling valves. Places where oxygen is stored in liquid or gaseous form should be marked clearly and legibly, providing information related to potential hazard. Employees hired to work in execution of processes that make use of liquid oxygen should not wear any jewellery, watches etc. In the event of emission of liquid oxygen into the environment, this would help prevent potential frostbite. During the execution of welding works (using acetylene-oxygen method) an issue of particular importance is that proper ventilation inside premises should be assured. An important method of limiting the possibility 
of a gas leak, which nevertheless is quite often trivialised, is securing the cylinder from falling. Potential fires should be extinguished by a water jet. If live electrical appliances are present, it is recommended to use carbon dioxide extinguishers. Should a gas cylinder fall down, apart from it becoming unsealed this could lead also to injuries of the employees: the cylinder may fall on an extremity of a person being nearby, and injuries may be caused by a cylinder moving quickly under the impact of the recoil force as a result of gas release as such [1]-[3].

\section{EXAMPLES OF INCIDENT INVOLVING CYLINDERS WITH OXYGEN}

\subsection{Explosion of benzene vapour caused by presence of liquid oxygen in the surroundings} (Japan, 1991)

The incident took place in an establishment manufacturing ceramic elements for needs of the electronic industry. The first phase of ceramics production is preparation of the mould sand. The crushed raw material (powder consisting primarily of silica and aluminium oxide), including solvent (benzene), is mixed until a uniform mass has been obtained. Liquid nitrogen is added to assure drying (at a temperature of $-196^{\circ} \mathrm{C}$ ). Ceramic elements obtained in such a way were then hauled to the oven with the use of a shovel made of stainless steel. At that exact moment an explosion took place.

As oxygen vaporisation temperature is $-183^{\circ} \mathrm{C}$, the most likely scenario of the incident was the creation of the oxygen condensed phase in nitrogen used in the adopted technological process. During manual hauling of ceramics to the dryer, benzene vapour at a higher oxygen concentration would cause an explosion. It was assumed that a mechanical spark created during the impact of steel shovel on the device housing used for manufacturing of ceramics would serve as a source of ignition.

As a consequence of the accident two employees lost their lives, and one sustained injuries. The entire establishment was destroyed (mill, pumps with accessories and mixer). The explosion also contributed to losses also in the adjacent plant [4], [5].

2.2 Death of employee due to damage of valve in cylinder filled with compressed oxygen (India, 2013)

The incident took place during manual hauling of a cylinder with compressed air. An employee of an Indian transport company along with two other persons were loading the cylinder onto a truck. As they did not have at their disposal no cart for transport of cylinders or any other suitable equipment, loading was done manually. The cylinders were rolled over the subgrade at a certain angle. The cylinder valve was next to the employee's stomach, who was supporting the cylinder from falling to the ground. Damage was caused to the valve of a cylinder filled up to the pressure of $20 \mathrm{MPa}$. The force generated by decompressing gas led to ejection of the damaged cylinder valve directly into the employee's stomach, and as an effect his being thrown ca. 6 metres away. As a consequence of sustained internal injuries, the employee dies on the spot.

The commission appointed to examine the accident found that damage to the valve was caused by progressing corrosion and the method of hauling the cylinder containing compressed oxygen has proven to be another element in the sequence of unfavourable events due to generated vibrations [6]-[8]. 


\section{TESTS ON TESTING GROUNDS CONDUCTED UNDER THE PROJECT}

Under the project called "Development of methods for neutralisation of potential explosion of selected cylinders containing technical gases, including alternative powering sources in the fire environment for the needs of rescuers participating in rescue and extinguishing actions" implemented under programme 6 for state security and defence financed by the National Centre for Research and Development carried out by a research and industrial consortium, the leader of which is the Main School of Fire Service and the Warsaw University of Technology, Gdańsk University of Technology, Scientific and Research Centre for Fire Protection in Jozefow - the Józef Tuliszkowski State Research Institute, Corona Sp. Z.O.O. a series of tests has been performed on testing grounds to identify phenomena taking place in cylinders (containers) present in a fire environment, including also cylinders containing oxygen.

Fires, during which cylinders and containers with technical gases are present, are particularly difficult to extinguish, and entail a significant risk both for persons present in the direct vicinity of the incident, and for the rescuers participating in the extinguishing action. Even if cylinders containing technical gases present in the impact range of the fire and of high temperatures do not explode, due to the necessity of evacuating people for a longer time (as regards acetylene cylinders, this period is 24 hours) frequently considerable material and social losses are sustained.

Table 1 presents a collective listing of test results for cylinders with oxygen.

Table 1: Summary of results for test of oxygen cylinders.

\begin{tabular}{|c|c|c|c|c|c|c|c|}
\hline Gas & $\begin{array}{l}\text { Type of } \\
\text { heating }\end{array}$ & $\begin{array}{l}\text { Heating time } \\
\text { until } \\
\text { explosion/ } \\
\text { neutralisation }\end{array}$ & $\begin{array}{c}\text { Initial } \\
\text { pressure } \\
\text { [bar] }\end{array}$ & $\begin{array}{c}\text { Final } \\
\text { pressure } \\
{[\mathrm{bar}]}\end{array}$ & $\begin{array}{l}\text { Explosion/ } \\
\text { neutralisation }\end{array}$ & $\begin{array}{l}\text { Number } \\
\text { of } \\
\text { fragments } \\
\text { and max. } \\
\text { range }[\mathrm{m}]\end{array}$ & Comments \\
\hline Oxygen & $2 \mathrm{P}$ & 25'23" & 150 & 262 & $P$ & $1 / 27+33$ & $\begin{array}{l}\text { Cylinder } \\
\text { bounced } \\
\text { but was not } \\
\text { broken }\end{array}$ \\
\hline Oxygen & B & $5^{\prime} 10^{\prime \prime}$ & 155 & 362 & W & $4 / 149$ & $\begin{array}{l}\text { One of the } \\
\text { fragments } \\
\text { achieved } \\
\text { the velocity } \\
\text { of ca. } \\
50 \mathrm{~m} / \mathrm{s}\end{array}$ \\
\hline Oxygen & $4 \mathrm{P}$ & 7'50" & 155 & 329 & W & $3 / 198$ & $\begin{array}{c}\text { Occurrence } \\
\text { of a shock } \\
\text { wave }\end{array}$ \\
\hline Oxygen & $4 \mathrm{P}$ & $5^{\prime 26 "}$ & 156 & 292 & W & $1 / 148$ & $\begin{array}{l}\text { Cylinder } \\
\text { exploded } \\
\text { prior to the } \\
\text { planned } \\
\text { water } \\
\text { cooling }\end{array}$ \\
\hline Oxygen & $4 \mathrm{P}$ & $30^{\prime} 00^{\prime \prime}$ & 159 & $\begin{array}{c}(235) / \\
164\end{array}$ & $P$ & $1 / 48$ & $\begin{array}{c}\text { In the first } \\
\text { neutralisati } \\
\text { on phase - } \\
\text { water } \\
\text { cooling }\end{array}$ \\
\hline $\begin{array}{c}\text { Oxygen } \\
\text { +acetyle } \\
\text { ne }\end{array}$ & B & $3^{\prime} 28 "$ & $\mathrm{C} 2 \mathrm{H} 2-21$ & $\mathrm{C} 2 \mathrm{H} 2-28$ & $\mathrm{P}+\mathrm{P}$ & $\begin{array}{c}\mathrm{C} 2 \mathrm{H} 2- \\
1 / 92\end{array}$ & \\
\hline
\end{tabular}


LEGEND: $2 \mathrm{P}$ - heating with two burners, $4 \mathrm{P}$ - heating with four burners, $\mathrm{B}$ - heating in petrol pool, $\mathrm{P}$ - neutralisation by shooting through, $\mathrm{K}$ - neutralisation using a hollow charge, $\mathrm{H} 2 \mathrm{O}$ - water cooling, $\mathrm{W}$ - explosion, $\mathrm{Z}$ - gas ejection through the safety valve. The tests have also shown that overshot oxygen cylinders are ejected into the air to a considerable distance, and during the flight they tumble forcefully [9]. Once the projectile has passed through the cylinder mantle, the generated aperture serves as an initial point of an exothermal reaction causing the burning out of a hole with a diameter of $7-10 \mathrm{~cm}$. The flowing out oxygen and products of the combustion process of the cylinder wall form a kind of a rocket engine characterised by a considerable propulsive thrust, sufficient to move the shot cylinder at a significant speed (Fig. 1).

In one of the scenarios a cylinder containing oxygen was heated up with two LPG burners with a calorific capacity of $50 \mathrm{~kW}$ each. After a period of 25 minutes 23 seconds since ignition of the burners, pressure in the cylinder achieved 260 bar and the cylinder was shot through with a.308 Lapua Lock Base $170 \mathrm{~g}$ bullet. The projectile broke through the front part of the cylinder. Oxygen flowing out from the opening in the cylinder caused ignition of steel of which the cylinder mantle had been made (a kind of a jet engine was created). As a consequence, during the flight the cylinder very quickly rolled over and over (Fig. 2). The flame had a maximum length of ca. $2 \mathrm{~m}$ and kept burning for 2 seconds. After that period the entire oxygen has left the cylinder. The cylinder has hit the ground at a distance of $27 \mathrm{~m}$ from the place where it had been shot, and then after bouncing off the ground it flew 33 metres more. The burnt-out hole had a diameter of ca. $65 \mathrm{~mm}$ (Fig. 1) Fig. 3 presents changes in pressure and gas temperature in the cylinder.

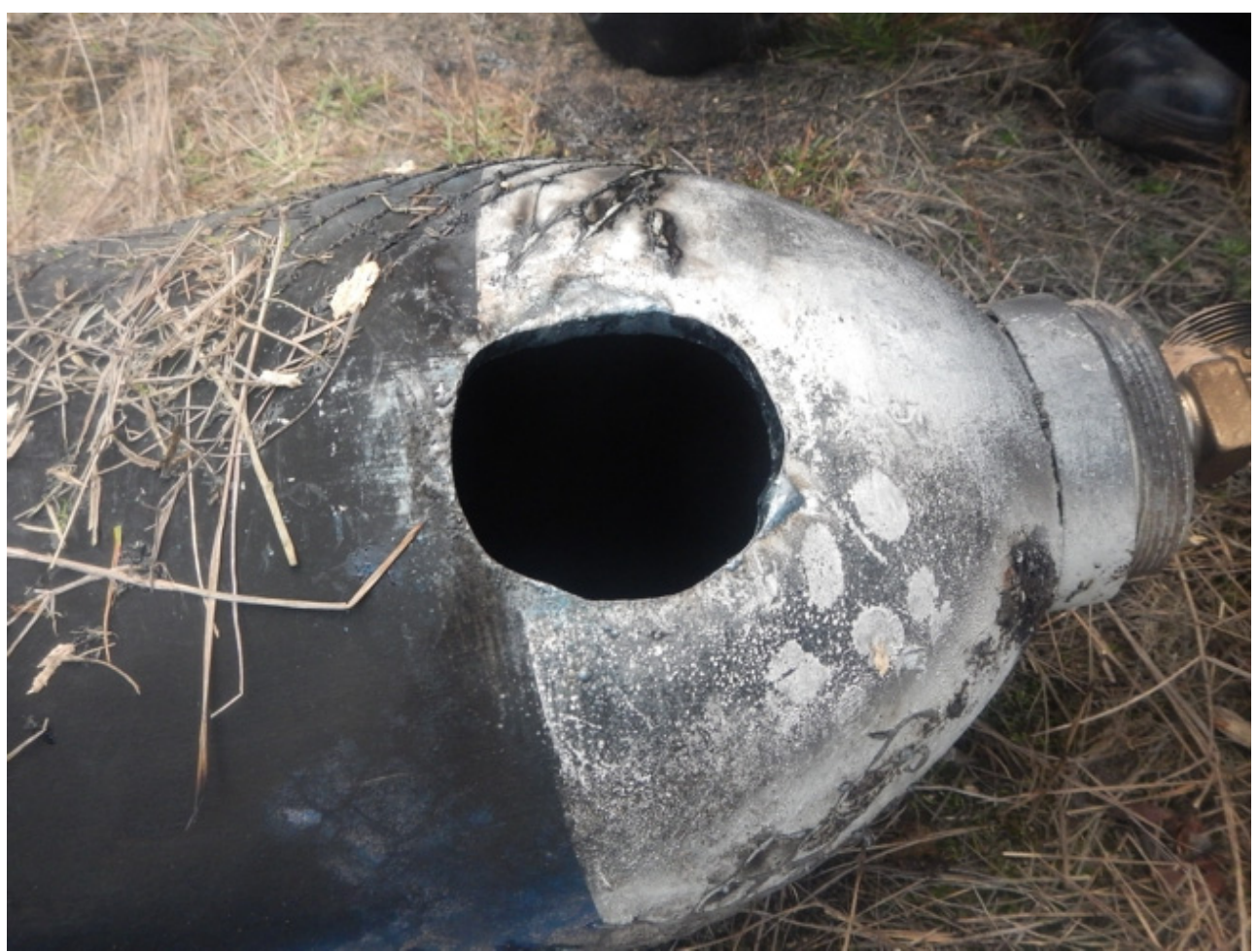

Figure 1: Opening burnt out in an oxygen cylinder wall. 


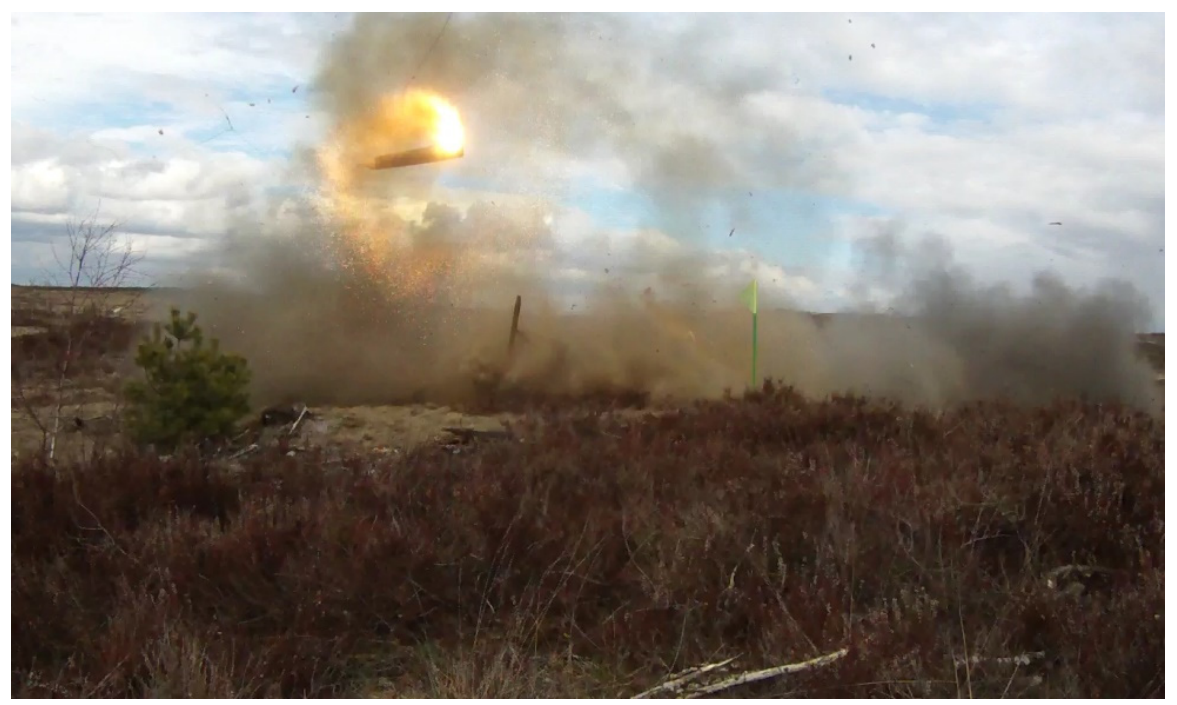

Figure 2: Tumbling oxygen cylinder following its being shot through by a projectile.

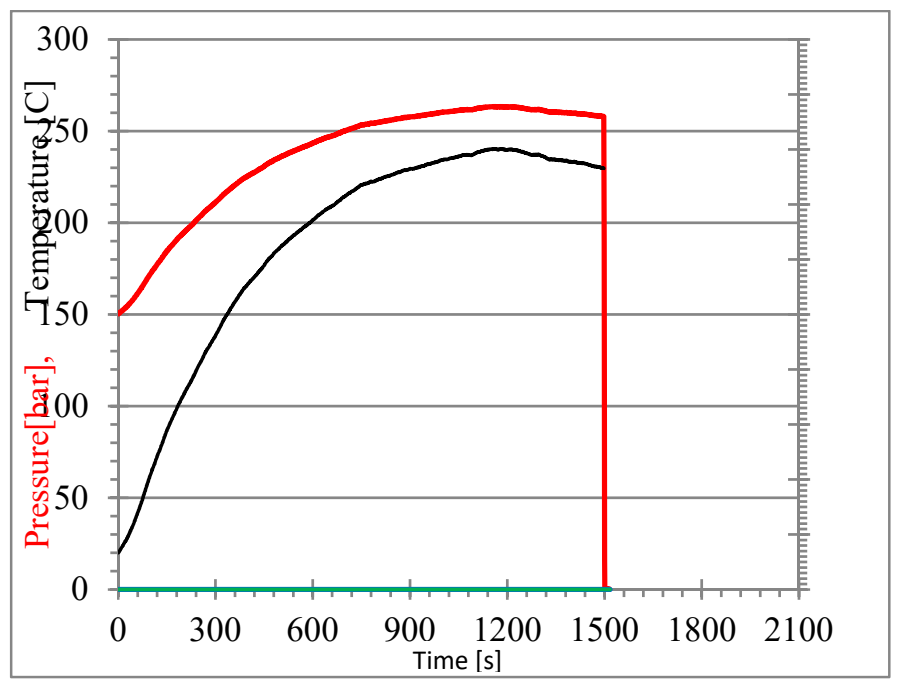

Figure 3: Pressure in cylinder and the corresponding temperature.

In the following experiment the cylinder containing oxygen was placed in a tub filled with a mixture of gasoline and diesel oil at a ratio of 2:1. After 5 minutes and 12 seconds the pressure has achieved 362 bar and the cylinder has burst. The bottle has been burst unto four large fragments (Fig. 4), one of which (marked by a red arrow on the figure) flew over a distance of $149 \mathrm{~m}$ with an initial velocity of ca. $50 \mathrm{~m} / \mathrm{s}$. Fig. 5 shows fragments collected from the foregrounds. Fig. 6 presents changes of pressure and temperature of gas in the bottle. 


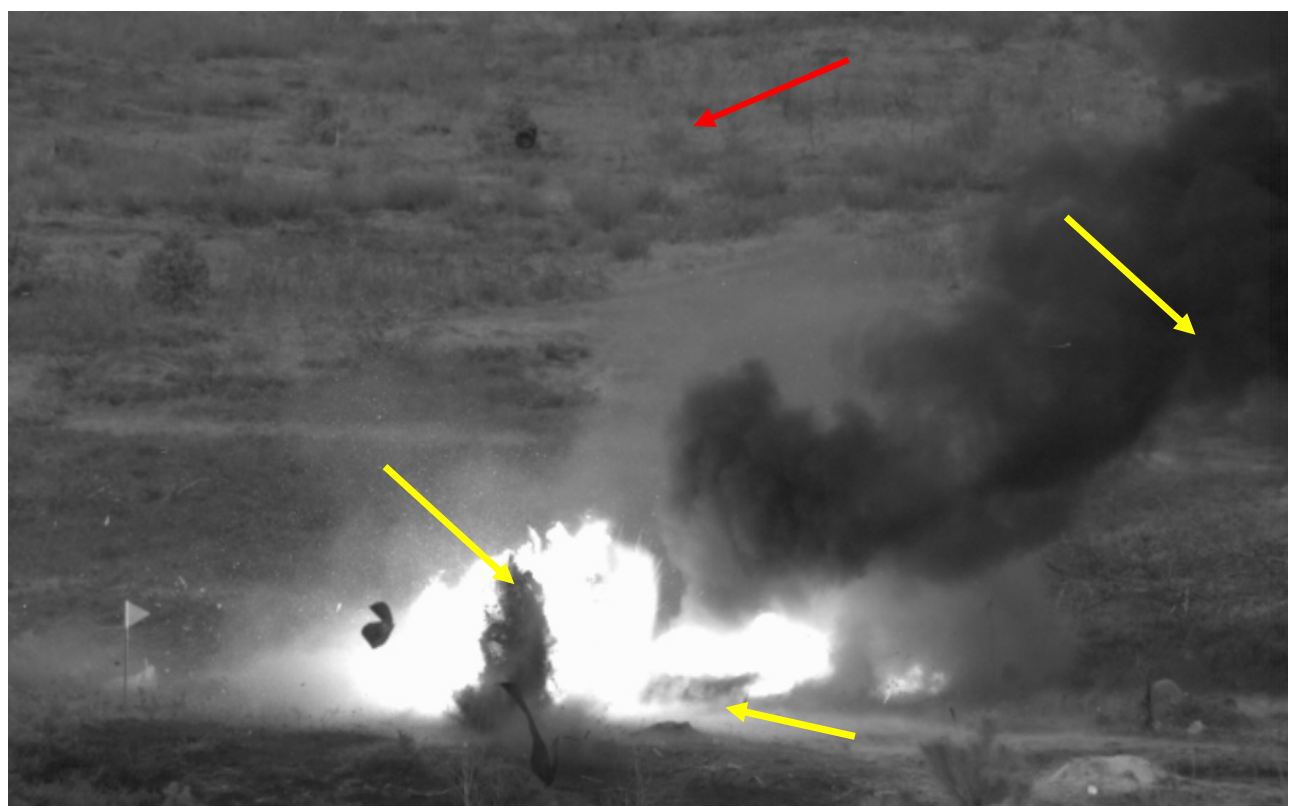

Figure 4: Explosion of an oxygen cylinder. Arrows point to formed cylinder fragments.

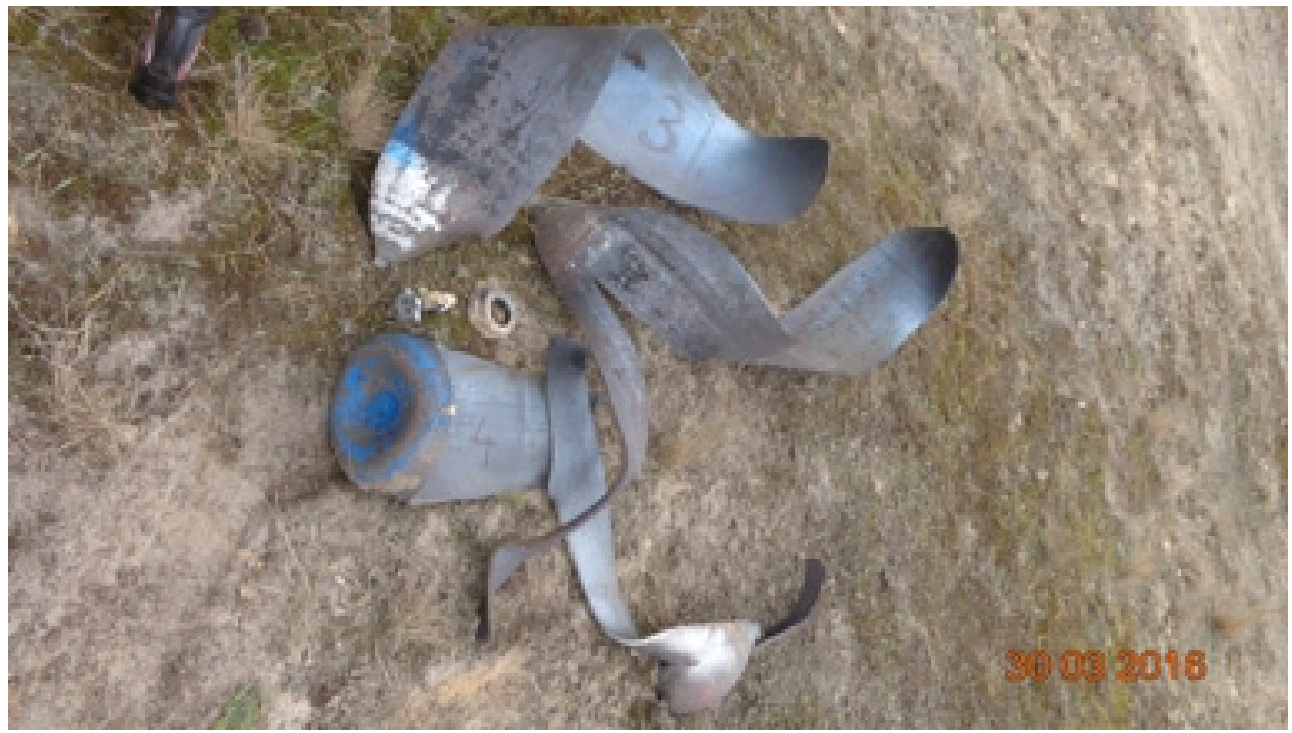

Figure 5: Fragments formed as a result of explosion of cylinder with oxygen. 


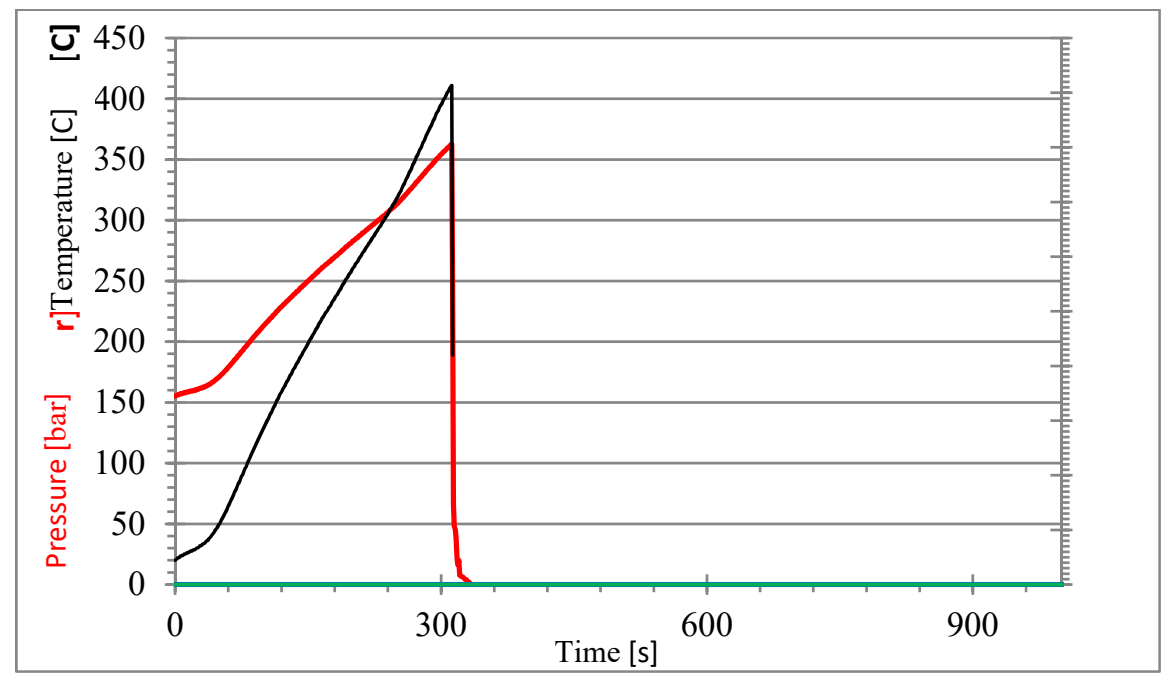

Figure 6: Pressure in oxygen cylinder and the corresponding gas temperature.

In the subsequent scenario the oxygen cylinder was heated by four burners fired by LPG with a calorific capacity of ca. $50 \mathrm{~kW}$ each. It was assumed that once a pressure of $300 \mathrm{bar}$ was achieved, the heating would be turned off and the cylinder would be cooled with the use of water. Unfortunately, after 5 minutes and 26 seconds, at a pressure of 292 bar the cylinder has exploded. The mantle of the burst cylinder was ejected into air (see arrow on Fig. 7) and flew over a distance of $148 \mathrm{~m}$. A mantle of burst cylinder is visible on Fig. 8. Fig. 9 presents pressure and temperature of gas in the cylinder in this experiment.

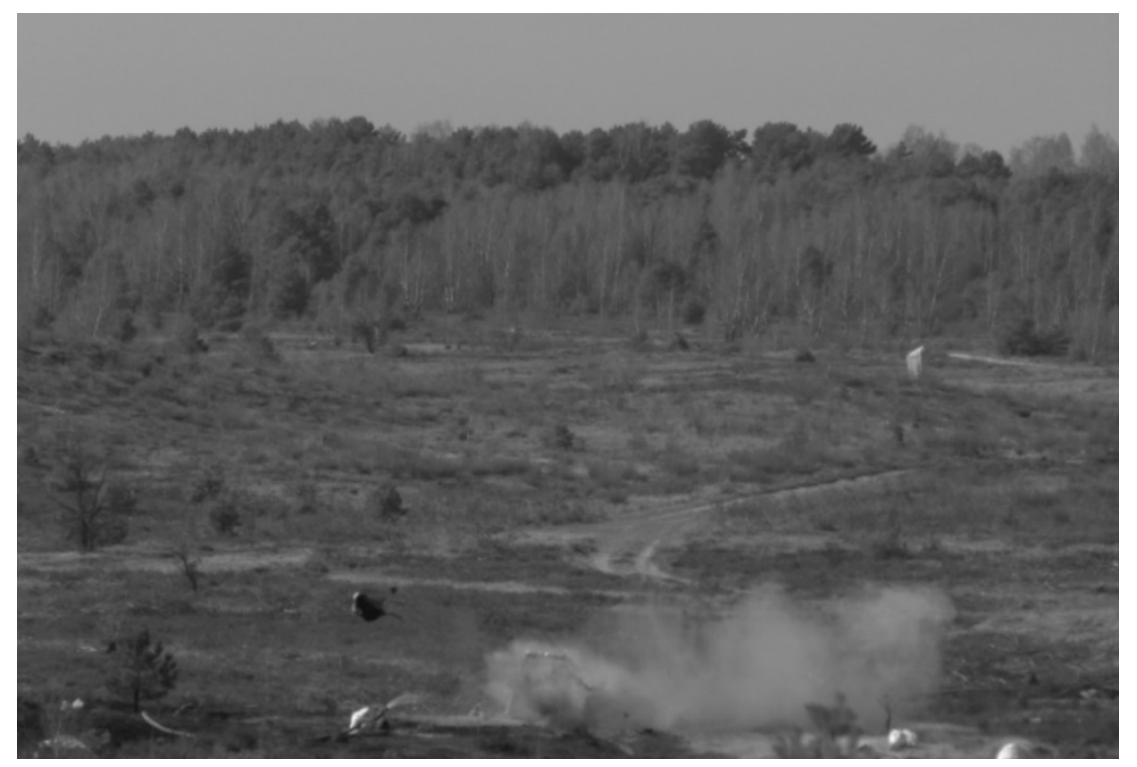

Figure 7: Explosion of oxygen cylinder. 


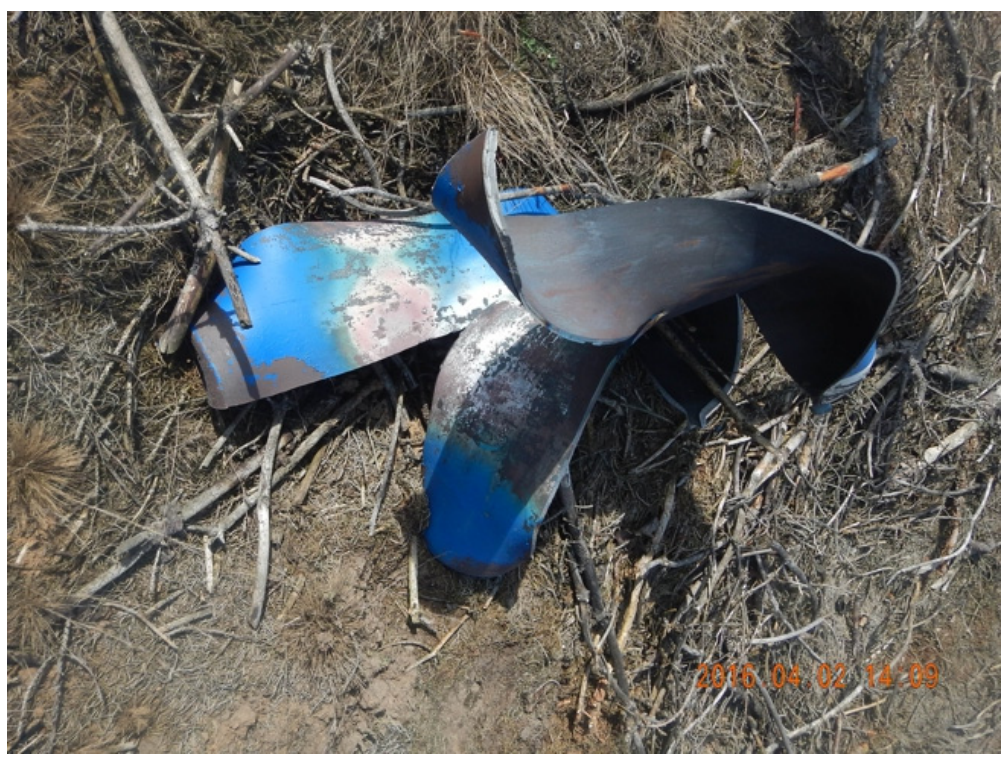

Figure 8: Mantle of exploded oxygen cylinder.

In one of the experiments the oxygen cylinder was heated up by four LPG burners with a calorific capacity of ca. $50 \mathrm{~kW}$ each. Once the pressure of 230 bar has been achieved, the heating was discontinued and water cooling was started. After the lapse of 30 minutes since the start of the experiment the cylinder was shot through. The cylinder was ejected into the air and tumbling flew over $48 \mathrm{~m}$ (Fig. 10). Fig. 11 presents pressure and temperature of gas in the cylinder.

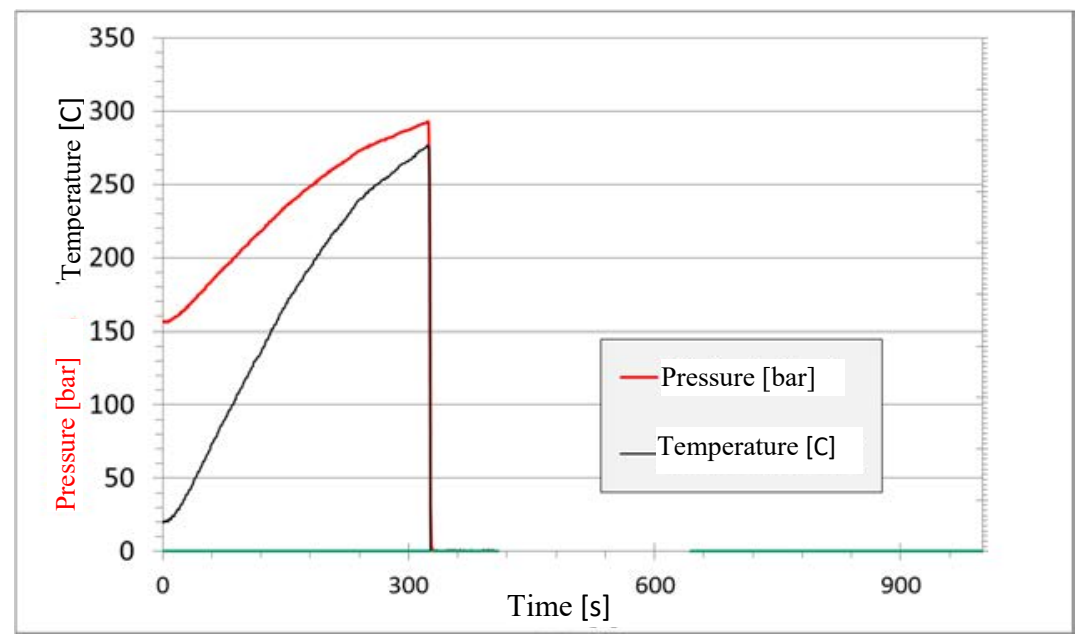

Figure 9: Gas pressure and temperature in cylinder. 


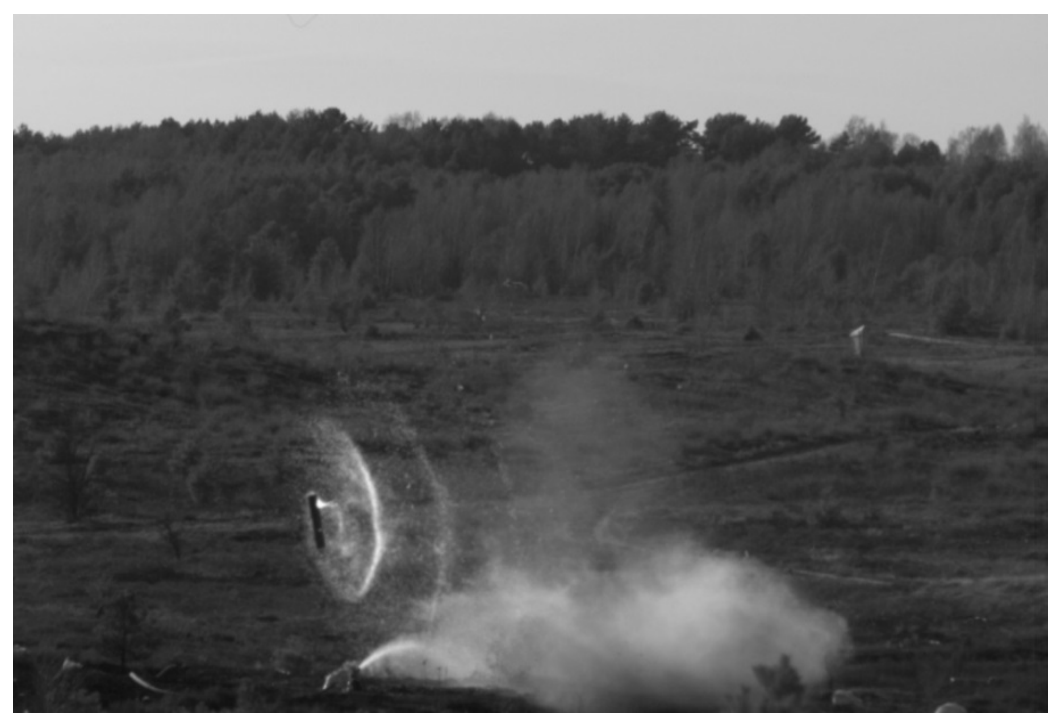

Figure 10: Rotating cylinder with oxygen.

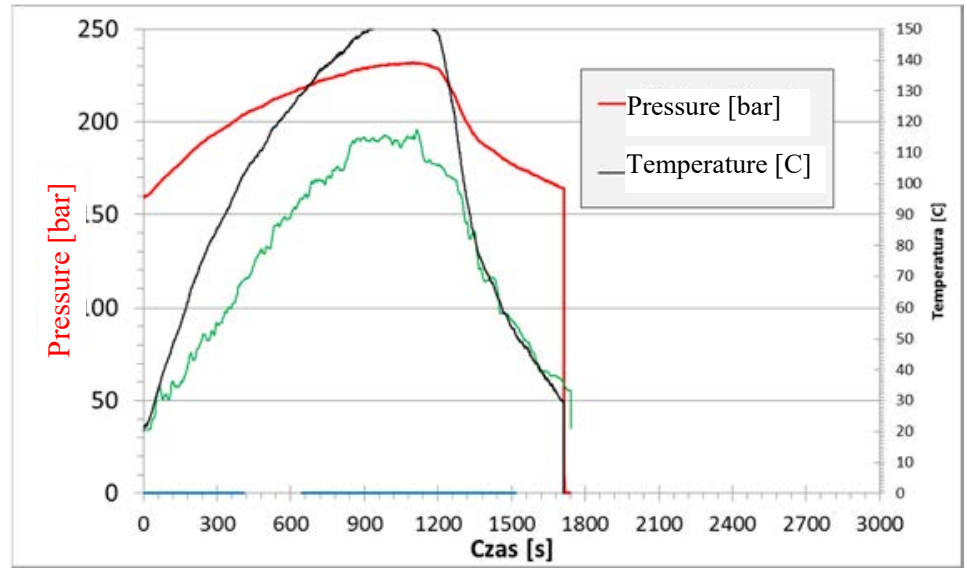

Figure 11: Gas pressure and temperature in the cylinder.

During the subsequent experiment two cylinders containing different gases was subjected to fire: with oxygen and with acetylene. According to the adopted scenario a signal for neutralisation of the acetylene cylinder was an increase in acetylene pressure from the initial value of 21 bar to 28 bar. This increase took place after 3 minutes and 35 seconds of the cylinder remaining in a highly intense flame generated by combustion of 201 of kerosene and 101 of diesel oil. The cylinder containing acetylene was shot through two times as the first one. As a consequence, openings were formed through which gas was released, which has immediately become ignited, and burnt with a quietly flickering flame. Afterwards the oxygen cylinder has been shot through. In line with preceding tests, overshooting of the cylinder wall caused its ejection to a considerable distance (92 m). 
Emergency incidents involving cylinders containing oxygen are connected with the occurrence of diverse threats. Characteristic scenarios of emergency incidents comprise the following:

- $\quad$ physical explosion of the cylinder with generation of an overpressure wave,

- fire ball after BLEVE explosion of flammable medium,

- jet fire, if there is additionally a flammable medium,

- gas emission (without ignition),

- intensification of pool fire of a flammable medium in the presence of a cylinder containing oxygen,

- explosion of a cloud of flammable vapour (Vapour Cloud Explosion - VCE/ Unconfined Vapour Cloud Explosion UVCE).

- $\quad$ fragmenting.

For needs of rescue actions an analysis was performed of the most complex incidents, which posed the biggest hazards and generating the biggest hazardous zone.

A review of results from the viewpoint of carrying out actions and entry of the rescuers to the hazardous zone has shown that the critical value of the heat flux density, at which a rescuer may continue working (serious bodily injuries), is considered to be $12,5 \mathrm{~kW} / \mathrm{m}^{2}$, and for an overpressure wave having a value of over $8 \mathrm{kPa}(1 \%$ injuries to eardrums and injuries caused by fragments).

One of the factors recorded during experimental testing was the size of the fir e ball and the range of fragments created during explosion of the cylinder. The range of a fireball for flammable gases was in the majority of cases contained within a zone of $50 \mathrm{~m}$. This is a zone in which in a normal situation the commander would decide to have rescuers evacuated earlier. Hence in a direct way no injuries caused by burns originating from the fire or heat flux generated by the fire should be expected. A much more dangerous situation took place following a physical explosion of containers and movement of fragments generated during fragmentation of the plating. During fragmentation cylinders containing oxygen formed as a rule 1-4 fragments, the biggest range of which amounted to ca. $200 \mathrm{~m}$. Fires or other emergencies involving cylinders with compressed air stored in cylinders or containers are frequently classified as incidents falling under chemical and ecological rescuing. The Polish rules of chemical and ecological rescuing defined a division into basic actions, the so-called "basic scope" executed by all fire protection units, and the "specialist scope", implemented by the Specialist Chemical and Ecological Rescuing Group.

The general principles adopt the rule of safety, which imposes the necessity of adopting in the first phase of activities a distance from the incident involving flammable gases not smaller than $150 \mathrm{~m}$ and assure the possibility of withdrawal from the place of incident, or 50 $\mathrm{m}$ for other types of incidents, during which there are no signs of emissions, leak or explosion hazard.

To recapitulate, a review of the compiled results allowed the devising of the following conclusions:

- the impact range of fragments constitutes the major hazard for people, the infrastructure and the surroundings, and is concurrently the least predictable,

- the smallest hazard is posed by incidents connected with a jet fire, pool fire or ball fire, the impact range of which does not exceed $100 \mathrm{~m}$, 
- the biggest hazard is posed by injury by fragments formed during explosion of cylinders, the range of which, depending on the type of cylinder and stored gas, may be $200 \mathrm{~m}$ for oxygen and acetylene.

\section{ACKNOWLEDGEMENTS}

The authors gratefully acknowledge the financial support from National Centre for Research and Development by the project for state defence and security DOB-BIO6/02/50/2014 called: "Development of methods for neutralisation of explosion risk of selected cylinders containing technical gases, including alternative powering sources in a fire environment for the needs of rescuers participating in rescue and extinguishing actions".

\section{REFERENCES}

[1] British Compressed Gases Association, Technical Report 2: The Probability of fatality in oxygen enriched atmospheres due to spillage of liquid oxygen 2013.

[2] Carson, P.A. \& Mumford C.J., Hazardous Chemicals Handbook, ButterworthHeinemann, Oxford, 2013.

[3] Hidenori, M., Explosion hazard when handling liquid nitrogen. Safety engineering 172, pp. 47-53, 1993.

[4] High Pressure Gas Safety Inst. Of Japan. Air liquefaction separator. Explosion of drawoff piping of the hydrocarbon from filter removing hydrocarbons from the liquefied oxygen. Accident examples of Petroleum refinery and petrochemical unit. pp. 156-162, 1995.

[5] High Pressure Gas Safety Inst. of Japan. High-pressure gas protection overview. pp. 246-252, 1992.

[6] Kogaku, K., Fire and explosion in the presence of excess oxygen. Safety engineering 203 pp. 122-127, 1998

[7] Millo, T. \& Piyush, S., Penetrating Missile Injury by Sudden Oxygen Release from Compressed Oxygen Cylinder: A case Report, Journal of Indian Academy of Forensic Medicine, 35, pp. 392-397, 2013.

[8] Occupational Safety and Health Association, Accident Case Studies Report no. 0905.

[9] WSH Council Fact Sheet, Safe handling of compressed gas cylinders. 